\title{
Molecular identification of Lactobacillus spp. associated with puba, a Brazilian fermented cassava food
}

\author{
S.M. Crispim ${ }^{1}$, A.M.A. Nascimento ${ }^{2}$, P.S. Costa $^{2}$, J.L.S. Moreira ${ }^{2}$, A.C. Nunes ${ }^{2}$, \\ J.R. Nicoli ${ }^{1}$, F.L. Lima ${ }^{3}$, V.T. Mota ${ }^{1}$, R.M.D. Nardi ${ }^{1}$ \\ ${ }^{1}$ Departamento de Microbiologia, Instituto de Ciências Biológicas, \\ Universidade Federal de Minas Gerais, Belo Horizonte, MG, Brazil. \\ ${ }^{2}$ Departamento de Biologia Geral, Instituto de Ciências Biológicas, \\ Universidade Federal de Minas Gerais, Belo Horizonte, MG, Brazil. \\ ${ }^{3}$ Centro de Ciências da Natureza, Universidade Estadual do Piauí, Teresina, PI, Brazil.
}

Submitted: April 29, 2011; Approved: July 2, 2012

\begin{abstract}
Puba or carima is a Brazilian staple food obtained by spontaneous submerged fermentation of cassava roots. A total of 116 lactobacilli and three cocci isolates from 20 commercial puba samples were recovered on de Man, Rogosa and Sharpe agar (MRS); they were characterized for their antagonistic activity against foodborne pathogens and identified taxonomically by classical and molecular methods. In all samples, lactic acid bacteria were recovered as the dominant microbiota $\left(7.86 \pm 0.41 \log _{10}\right.$ CFU/g). 16S-23S rRNA ARDRA pattern assigned 116 isolates to the Lactobacillus genus, represented by the species Lactobacillus fermentum (59 isolates), Lactobacillus delbrueckii (18 isolates), Lactobacillus casei (9 isolates), Lactobacillus reuteri (6 isolates), Lactobacillus brevis (3 isolates), Lactobacillus gasseri (2 isolates), Lactobacillus nagelii (1 isolate), and Lactobacillus plantarum group (18 isolates). recA gene-multiplex PCR analysis revealed that $L$. plantarum group isolates belonged to Lactobacillus plantarum (15 isolates) and Lactobacillus paraplantarum (3 isolates). Genomic diversity was investigated by molecular typing with rep (repetitive sequence)-based PCR using the primer ERIC2 (enterobacterial repetitive intergenic consensus). The Lactobacillus isolates exhibited genetic heterogeneity and species-specific fingerprint patterns. All the isolates showed antagonistic activity against the foodborne pathogenic bacteria tested. This antibacterial effect was attributed to acid production, except in the cases of three isolates that apparently produced bacteriocin-like inhibitory substances. This study provides the first insight into the genetic diversity of Lactobacillus spp. of puba.
\end{abstract}

Key words: puba, carimã, fermented food, Lactobacillus spp., cassava, antagonism.

\section{Introduction}

Puba or carimã is a staple Brazilian food produced from fermented cassava (Manihot esculenta, Crantz) in small-scale factories or under empirical household conditions. Methods of puba preparation vary from locality to locality. Puba manufacture is based on the old empirical knowledge of several Brazilian indigenous tribes, whose traditional methods of preparation have changed little over time. This technology was exported to West Africa and pre- sumably adapted locally, resulting in many cassava-fermented products, such as foo-foo and lafun (Almeida et al., 1983).

A common method adopted in Northeast Brazil comprises the following steps: peeled or unpeeled cassava roots are washed, cut into small sized pieces and submerged for a period of three to seven days at ambient temperature (average annual: $27^{\circ} \mathrm{C}$ ) in large pots containing fresh water. During this period of steeping, retting occurs, and the cassava roots become soft. At this stage, the roots are removed

Send correspondence to R.M.D. Nardi. Departamento de Microbiologia, Instituto de Ciências Biológicas, Universidade Federal de Minas Gerais, Avenida Antônio Carlos 6627, 31270-901 Belo Horizonte, MG, Brazil. E-mail address: nardi@icb.ufmg.br. 
from the water and forced by hand through a fine mesh to remove fibrous materials. The sieved mash is washed and allowed to settle, and the water is decanted. The resulting mash is placed into a cloth bag, and the excess water is pressed out by squeezing the bag to produce wet puba $(50 \%$ moisture). Alternatively, this material can be sun-exposed to produce dry $p u b a$, a type of flour with approximately 13\% moisture (Almeida et al., 1983). Both are largely used in the North and Northeast of Brazil to manufacture, for instance, carimã cake, carimã couscous, and cassava paste porridge (Fernandes, 2009).

Cassava fermentation for the production of puba is associated with the fermentative activities of bacteria and yeasts (Almeida et al., 1983). Lactic acid bacteria (LAB) are predominant during all stages of cassava fermentation and contribute to the development of characteristic properties such as taste, aroma, visual appearance, texture, shelf life and safety. This fermentation is important because it removes considerable amounts of cyanide and produces antimicrobial compounds including organic acids, hydrogen peroxide, and other active low molecular weight metabolites and bacteriocins (Adams and Nicolaides, 1987; Holzapfel, 2002).

In this study, market samples of puba from Northeast Brazil were tested to enumerate and identify predominant LAB populations. Additionally, possible antagonistic activities within and between $\mathrm{LAB}$ and against some foodborne pathogenic bacteria were tested. The aim of this study was to recover Lactobacillus spp. from several puba samples by conventional plating methods and to genetically characterize them.

\section{Material and Methods}

\section{Sample collection and bacterial isolation}

Twenty samples of puba, which were homemade using the traditional method, were randomly purchased from different local markets in Teresina (Piauí state, located in the Northeast region of Brazil). Approximately $500 \mathrm{~g}$ of puba samples were collected aseptically with a sterile spoon into a sterile stomacher bag and transported immediately in a cooler containing ice to the laboratory for analyses. The sampling and experiments were carried out in duplicate.

Twenty-five grams of each sample were weighed and processed according to Lacerda et al. (2005). Appropriate dilutions were plated onto de Man, Rogosa and Sharpe agar (MRS, Difco, Detroit, USA) and incubated at $37^{\circ} \mathrm{C}$ for $72 \mathrm{~h}$ in an anaerobic chamber (Forma Scientific Company, Marietta, USA) containing an atmosphere of $85 \% \mathrm{~N}_{2}, 10 \% \mathrm{H}_{2}$ and $5 \% \mathrm{CO}_{2}$. After growth, colony forming units $\left(\log _{10} \mathrm{CFU} / \mathrm{g}\right)$ were quantified, and representative morphotypes of the highest dilutions were isolated for identification. Presumptive LAB were phenotypically characterized by Gram-staining and catalase activity.

\section{Molecular identification of $L A B$}

For identification, the chromosomal DNA of each isolate was extracted using a "Wizard Genomic DNA Purification" kit (Promega, Madison, USA) according to the manufacturer's instructions. PCR amplification of the intergenic segment between the 16S and 23S rRNA subunits was carried out, followed by amplified ribosomal DNA restriction analysis (ARDRA) as described by Moreira et al. (2005), modified to include the AvrII enzyme. Lactobacillus brevis ATCC 367, Lactobacillus casei ATCC 7464, Lactobacillus delbrueckii subsp. lactis ATCC 7830, Lactobacillus fermentum ATCC 9338, Lactobacillus gasseri ATCC 33323, Lactobacillus plantarum ATCC 8014 and Lactobacillus reuteri ATCC 55730 were used as controls.

The isolates presumptively identified by ARDRA as belonging to the $L$. plantarum group were subjected to $a$ posteriori species-specific recA gene-multiplex PCR analysis, which allows separation of the three closely related species of the L. plantarum group by comparing the size of their amplicons: $318 \mathrm{bp}$ for $L$. plantarum, $218 \mathrm{bp}$ for $L$. pentosus and $107 \mathrm{bp}$ for L. paraplantarum (Torriani and Dellaglio, 2001). L. plantarum ATCC1 4917, L. paraplantarum DSM 10667 and L. pentosus ATCC 8041 were used as controls.

The identification of the three cocci isolates was performed by partial sequence analysis of the 16S rDNA using the primers 27f (5'-AGAGTTTGATCCTGGCTCAG-3') and 1492r (5'-GGTTACCTTGTTACGACTT-3') (Guyot et al., 1998). Sequences were compared to $16 \mathrm{~S}$ rDNA data obtained from the Ribosomal Database Project (http://www.cme.msu.edu/RDP/html/index.html) and GenBank (http://www.ncbi.nlm.nih.gov).

\section{rep-PCR DNA fingerprinting}

rep-PCR genomic fingerprinting was performed using the ERIC2 primer (5'-AAGTAAGTGACTGGGGTG AGCG-3') (Versalovic et al., 1991). The PCR conditions were carried out according to Delfederico et al. (2005). ERIC-PCR amplicons were separated by $8 \%$ sodium dodecyl sulfate-polyacrylamide gel electrophoresis at $100 \mathrm{~V}$. The gels were stained in $12 \%$ silver solution and photographed. The fingerprints were analyzed using BioNumerics ver. 6.0 software (Applied Maths, St. Martens-Latem, Belgium). Digitalized gel images were converted and normalized using the $1 \mathrm{~kb}$ Plus DNA Ladder (Invitrogen Corporation, Camarillo, CA, USA). The similarity between sets of fingerprint patterns was calculated using the pairwise Pearson's product-moment correlation coefficient $(r$ value; these values are often represented by $\%$ similarity where an $r$ value of 1 is equivalent to $100 \%$ ). This approach compares the entire densitometric curves of the fingerprints (Hane et al., 1993). Cluster analysis of pairwise similarity values was performed using the unweighted pair-group 
method using arithmetic averages clustering algorithm (UPGMA).

\section{Determination of antagonistic activity}

LAB isolates were tested for antagonistic activity by the agar-spot assay (Schillinger and Lücke, 1989). The antagonistic activity was detected by the presence of a growth inhibition zone of the indicator strain around the spot of LAB. To exclude the effect of acid production, the antagonistic activity of the cell-free supernatant was confirmed after neutralization. Supernatants that gave positive results after neutralization were also tested for antagonistic activity after treatment with proteinase $\mathrm{K}(1 \mathrm{mg} / \mathrm{mL}$, Merck, Darmstadt, Germany). Then, the supernatants were tested against Bacillus cereus ATCC 11778 and Listeria monocytogenes ATCC 7664 using the agar well diffusion assay (Schillinger and Lücke, 1989).

\section{Results}

\section{LAB quantification and taxonomic assignment}

In total, 119 Gram-positive, catalase-negative presumptive LAB from MRS agar were isolated from commercial puba samples. Table 1 shows the result of enumeration and molecular identification of LAB recovered from the dominant microbiota of puba. The total count of the
LAB population varied from 7.18 to $8.73 \log _{10} \mathrm{CFU} / \mathrm{g}$. The analysis of endonuclease restriction patterns of $16 \mathrm{~S}-23 \mathrm{~S}$ rRNA spacers revealed seven different species: $L$. fermentum (59 isolates), L. delbrueckii (18 isolates), $L$. casei (9 isolates) L. reuteri (6 isolates), L. brevis (3 isolates), L. gasseri (2 isolates), and L. nagelii (1 isolate). ARDRA did not allow separation by species for the $L$. plantarum group. However, the species-specific recA gene-multiplex PCR allowed the identification of 18 isolates of the L. plantarum group as L. plantarum (15 isolates) and L. paraplantarum (3 isolates).

The three remaining cocci isolates, all from the same sample, were then identified by rRNA $16 \mathrm{~S}$ sequencing as Lactococcus lactis subsp. lactis, Lactococcus lactis subsp. cremoris and Leuconostoc pseudomesenteroides.

\section{ERIC-PCR fingerprinting}

We used interspersed repetitive sequence PCR to discern the genetic relationships among Lactobacillus isolates derived from the different puba samples. All reference strains had unique ERIC2-PCR fingerprint patterns and did not match any of the patterns obtained for the Lactobacillus isolates. Overall, the dendrograms revealed a high genetic heterogeneity among the lactobacilli isolate species with some exceptions. Some L. fermentum (puba 6, 7, 10, 11, 16 and 17) and L. plantarum isolates (puba 3 ) from the same

Table 1 - Total population levels and the distribution of lactic acid bacterial species recovered from different puba samples.

\begin{tabular}{|c|c|c|}
\hline Sample & Total counts $\left(\log _{10} \mathrm{CFU} / \mathrm{g}\right)$ & Identified species \\
\hline 1 & 8.09 & L. fermentum (1) ${ }^{\mathrm{a}}$ L. gasseri (1) L. plantarum (1) L. reuteri (1) \\
\hline 2 & 8.18 & L. fermentum (4) \\
\hline 3 & 7.67 & L. plantarum (3) \\
\hline 4 & 7.34 & L. fermentum (3) L. plantarum (1) \\
\hline 5 & 7.18 & L. brevis (2) L. casei (2) L. gasseri (1) L. reuteri (1) \\
\hline 6 & 7.85 & L. delbrueckii (7) L. fermentum (4) L. nagelii (1) L. plantarum (3) \\
\hline 7 & 7.74 & L. delbrueckii (2) L. fermentum (4) L. plantarum (2) \\
\hline 8 & 7.72 & L. delbrueckii (1) L. casei (2) L. fermentum (5) \\
\hline 9 & 8.59 & L. brevis (1) L. delbrueckii (1) L. fermentum (5) \\
\hline 10 & 8.34 & L. fermentum (4) \\
\hline 11 & 8.73 & L. fermentum (4) \\
\hline 12 & 7.97 & L. casei (2) L. delbrueckii (3) L. fermentum (6) \\
\hline 13 & 7.66 & L. casei (1) L. delbrueckii (2) L. plantarum (1) L. reuteri (4) \\
\hline 14 & 7.23 & L. casei (1) L. fermentum (2) L. paraplantarum (2) \\
\hline 15 & 7.78 & L. casei (1) L. delbrueckii (1) L. fermentum (2) \\
\hline 16 & 7.86 & L. fermentum (6) \\
\hline 17 & 7.34 & L. fermentum (4) \\
\hline 18 & 8.08 & L. fermentum (2) L. plantarum (1) \\
\hline 19 & 8.15 & L. delbrueckii (1) L. fermentum (3) L. paraplantarum (1) \\
\hline 20 & 7.84 & L. plantarum (3) L. lactis subsp. lactis $^{\mathrm{b}}$ (1) L. lactis subsp. cremoris $^{\mathrm{c}}$ (1) L. pseudomesenteroides ${ }^{\mathrm{d}}$ (1) \\
\hline Mean \pm SD & $7.86 \pm 0.41$ & \\
\hline
\end{tabular}

${ }^{\mathrm{a}}\left(\right.$ ) number of isolates. ${ }^{\mathrm{b}}$ Lactococcus lactis subsp. lactis. ${ }^{\mathrm{c}}$ Lactococcus lactis subsp. cremoris. ${ }^{\mathrm{d}}$ Leuconostoc pseudomesenteroides. 
puba sample showed indistinguishable fingerprints (Figures 1 and 2).

\section{Detection and partial characterization of the antagonistic activity}

Table 2 shows that all the LAB isolated from puba inhibited the growth of all the pathogenic bacteria tested, and that most of them also antagonized at least one of the Lactobacillus indicators. L. delbrueckii, L. nagelii and L. pseudomesenteroides isolates showed the lowest or no inhibition ability against the indigenous strains tested.

After neutralization of cell-free supernatants of all LAB isolates, only L. lactis subsp. lactis, L. lactis subsp. cremoris and one isolate of L. plantarum from puba 1 showed antimicrobial activity against $L$. monocytogenes and B. cereus. Complete inactivation of these antimicrobial activities was observed after treatment with proteinase $\mathrm{K}$ (data not shown).

\section{Discussion}

Cassava fermentation for puba production is a spontaneous process, whose microbiota is not well known. This study showed that LAB were isolated from commercial puba samples in population levels (7.18-8.73 $\log _{10} \mathrm{CFU} / \mathrm{g}$ ) slightly lower than those observed after $48 \mathrm{~h}$ of fermentation of lafun (8.7-8.9 $\left.\log _{10} \mathrm{CFU} / \mathrm{g}\right)$ and foo-foo (9.0 $\log _{10}$ CFU/g) (Padonou et al., 2009a; Brauman et al., 1996).

Using ARDRA for species identification, the LAB most frequently isolated from puba samples were $L$. fermentum, followed by L. delbrueckii and L. plantarum group. ARDRA failed to identify species for the $L$. plantarum group (L. plantarum, L. paraplantarum), show-

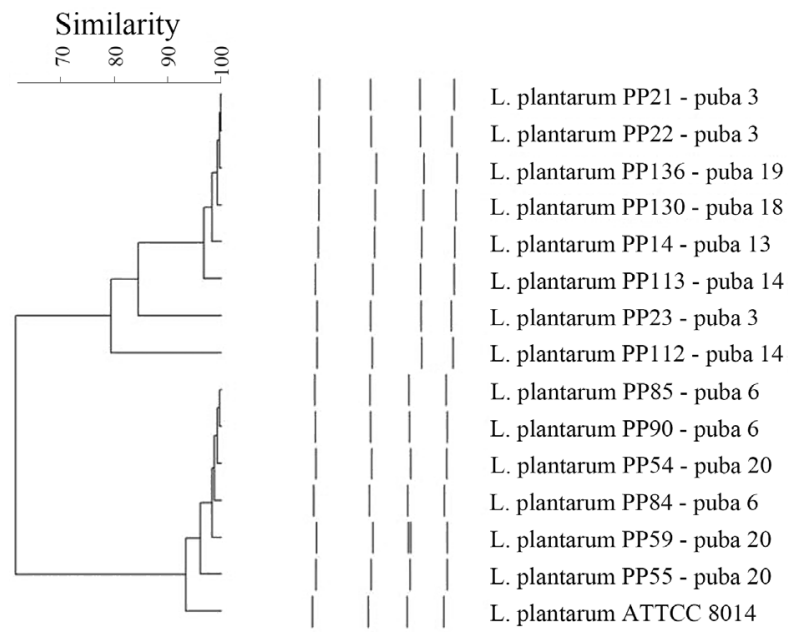

Figure 1 - Dendrogram showing the genetic relatedness among Lactobacillus plantarum from different puba samples as determined by ERIC PCR fingerprint analysis. Similarity (\%) between patterns was calculated using the Pearson coefficient, and data were sorted by UPGMA clustering. PP XX means the puba isolate number indicated by the dendogram. ing the same restriction profile with the restriction enzymes SphI, SspI, VspI and HincII (data not shown).

Interestingly, when isolated, L. delbrueckii was generally associated with other lactobacilli, and particularly, always with $L$. fermentum. These results confirm previous observations that $\mathrm{LAB}$ predominate in the fermentative processes of cassava and frequently in association with two to four different species isolated from each sample (Brauman et al., 1996), suggesting some possible synergetic phenomena. In the present study, $70 \%$ of the puba samples

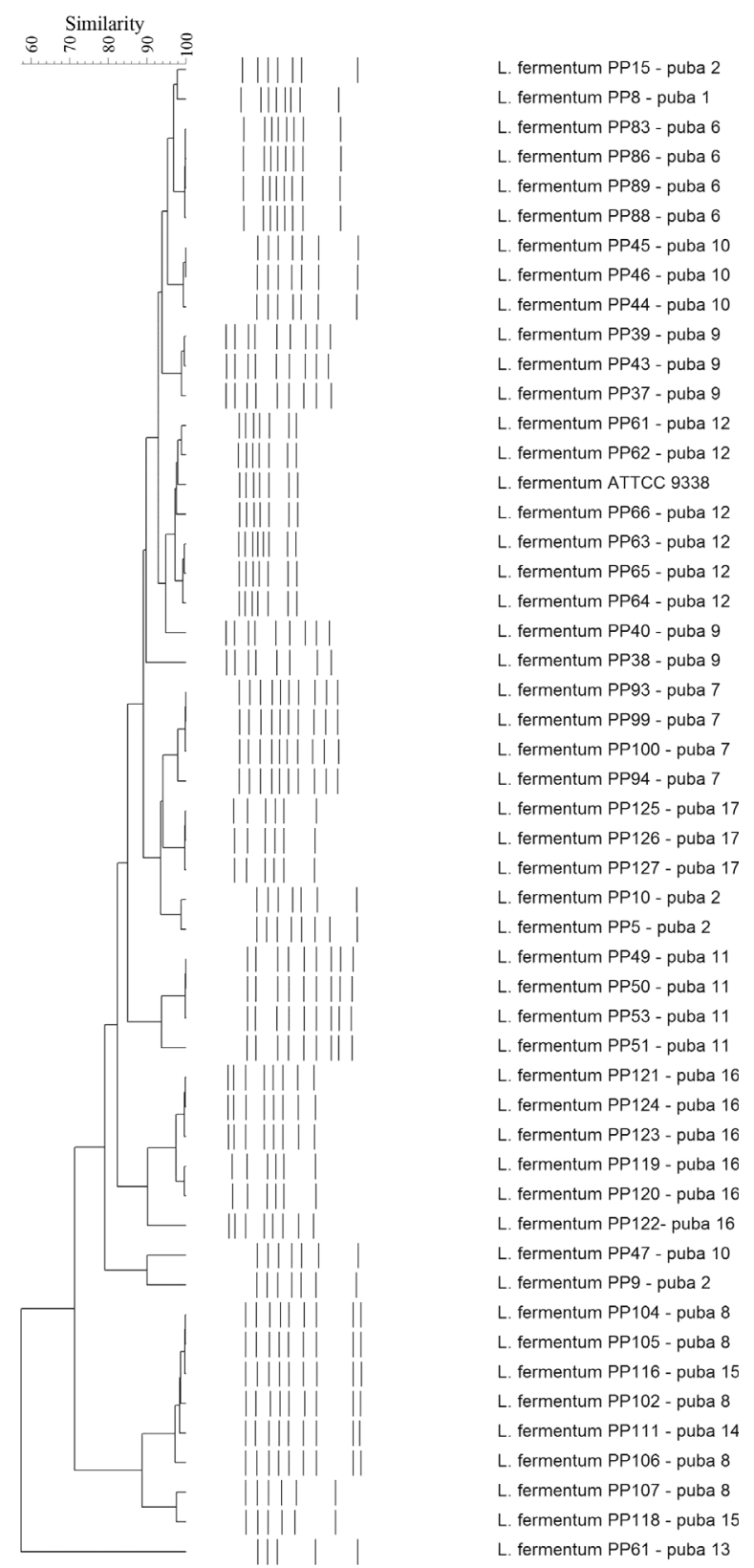

Figure 2 - Dendrogram showing the genetic relatedness among Lactobacillus fermentum from different puba samples as determined by ERIC PCR fingerprint analysis. Similarity (\%) between patterns was calculated using the Pearson coefficient, and data were sorted by UPGMA clustering. PP XX means the puba isolate number indicated by the dendogram. 
Table 2 - In vitro antagonistic activity of lactic acid bacteria from puba samples.

\begin{tabular}{|c|c|c|c|c|c|c|}
\hline \multirow[t]{2}{*}{ Species } & \multicolumn{6}{|c|}{ Indicator strains $\mathrm{s}^{\mathrm{a}}$} \\
\hline & Pathogenic strains & L. brevis & L. fermentum & L.casei & L. plantarum & L. delbrueckii \\
\hline L. fermentum $(59)^{\mathrm{b}}$ & $100^{\mathrm{c}}$ & 6.8 & 0 & 5.1 & 5.1 & 62.7 \\
\hline L. delbrueckii (18) & 100 & 5.6 & 0 & 0 & 0 & 0 \\
\hline L. plantarum (15) & 100 & 10.5 & 0 & 26.3 & 0 & 100 \\
\hline L. casei (9) & 100 & 11.1 & 33.3 & 0 & 111 & 55.5 \\
\hline L. reuteri (6) & 100 & 50.0 & 0 & 33.3 & 16.7 & 66.7 \\
\hline L. paraplantarum (3) & 100 & 0 & 0 & 25.0 & 0 & 75.0 \\
\hline L. brevis (3) & 100 & 0 & 0 & 33.3 & 0 & 33.3 \\
\hline L. gasseri (2) & 100 & 0 & 0 & 50 & 0 & 100 \\
\hline L. nagelii (1) & 100 & $-{ }^{d}$ & - & - & - & - \\
\hline L. lactis subsp. lactis (1) & & & 100 & & & - \\
\hline L. lactis subsp. cremoris (1) & & & 100 & & & - \\
\hline L. pseudomesenteroides (1) & 100 & - & - & - & - & - \\
\hline
\end{tabular}

${ }^{a}$ Pathogenic strains: Salmonella enterica serovar Typhimurium ATCC 13311; Listeria monocytogenes ATCC 7664; Staphylococcus aureus ATCC 12600, Bacillus cereus ATCC 11778; non-pathogenic strains: Lactobacillus brevis ATCC 367, Lactobacillus fermentum ATCC 9338, Lactobacillus casei subsp. rhamnosus ATCC 7469, Lactobacillus plantarum ATCC 8014, Lactobacillus delbrueckii subsp. lactis ATCC 7830 Lactobacillus fermentum ATCC 9338.

( ) number of isolates tested for each species.

${ }^{\mathrm{c}}$ Frequency (\%) of antagonistic activity of all isolates of each species against all pathogenic indicators or against each indigenous indicator.

${ }^{\mathrm{d}}$ When only one isolate was obtained for a species and tested against only one indicator strain, the frequency could not be calculated, and the results were presented as antagonism $(+)$ or not (-).

were associated with two, three or four LAB species in two, seven and five samples, respectively.

There are few reports concerning puba and other Brazilian fermented cassava products. Studying puba produced in the State of Bahia, Almeida et al. (1983) showed that during fermentation, Streptococcus, Lactobacillus and Leuconostoc population levels increased gradually until becoming predominant. Using ARDRA, Lacerda et al. (2005) identified prevalent lactobacilli associated with spontaneous fermentation during the production of sour cassava starch in Brazil as L. plantarum and L. fermentum, while Lactobacillus perolans and L. brevis were minor fractions of the populations. Lactobacillus pentosus and $L$. plantarum were the dominant bacteria present in all periods of evaluation of samples of cauim, a fermented beverage produced by Brazilian Amerindians (Almeida et al., 2007).

$\mathrm{LAB}$ were also the predominant microorganisms involved in the fermentation of lafun and foo-foo. Padonou et al. (2009a) showed that the dominant LAB in lafun was $L$. fermentum, followed by $L$. plantarum and Weissella confusa. In foo-foo, L. delbrueckii, L. fermentum, Lactococcus lactis and Leuconostoc mesenteroides were recovered during the fermentation process, whereas $L$. plantarum was the dominant species at the end of the process (Brauman et al., 1996). Studies of other African fermented cassava products reported that for gari and agbelima, L. plantarum group members were identified as dominant (Kostineck et al., 2005; Amoa-Awua et al., 1996).
To further explore the genetic relationships between Lactobacillus isolates, we performed ERIC2 PCR fingerprinting. This genomic fingerprinting technique has been successfully used for generating discriminatory polymorphisms from different species of Lactobacillus (Stephenson et al., 2009). The results obtained from genomic fingerprinting are in agreement with those of Stephenson et al. (2009) and revealed that the different isolates from the same species of Lactobacillus had isolate-specific patterns, indicating that these isolates are non-clonal. Furthermore, the $L$. fermentum isolates had more genetic heterogeneity among the Lactobacillus species investigated, as also reported by Kostinek et al. (2005).

Puba fermentation is carried out mainly by people living in regions with poor sanitary conditions. For this reason, the presence of LAB with high antimicrobial activity against the most frequent foodborne pathogenic bacteria is desirable. The predominance of Lactobacillus spp. observed in cassava fermented products is probably due to their well-known antagonistic characteristics (Holzapfel, 2002).

In the present study, some of the results from the in vitro antagonistic assays presented in Table 2 apparently contradicted those observed in situ (Table 1). For example, $43.8 \%$ of the L. fermentum isolates that showed in vitro antagonism against $L$. delbrueckii were associated with this bacteria species in puba samples. However, it is well known that in vitro results cannot always be extrapolated to in vivo or in situ conditions. This discrepancy may be ex- 
plained by the medium formulation of MRS agar used for the antagonistic assay, which is quite different from the puba composition. Another possible explanation could be a different sensitivity to antagonism between Lactobacillus isolates from $p u b a$ and the reference strains used as indicators.

Other results obtained in this study suggest that organic acid production was the most frequent mechanism responsible for the antagonism observed in the in vitro assays. Reduced $\mathrm{pH}$, in combination with the presence of undissociated organic acid, principally lactic acid, is responsible for most of the inhibitory effects observed (Adams and Nicolaides, 1997). In acidic food, the low $\mathrm{pH}$ will increase the proportion of undissociated acid present. When the undissociated acid passes through the plasma membrane into the higher $\mathrm{pH}$ of the cytoplasm, it will dissociate, acidifying the cytoplasm and releasing the anion. The accumulation of the ion $\mathrm{H}^{+}$can disrupt intracellular processes (Adams and Nicolaides, 1997).

Due to acidification, the environment becomes selective against less acid-tolerant bacteria and preserves the products from pathogenic and food spoiling microorganisms (Holzapfel, 2002). Indeed, the minimum $\mathrm{pH}$ values allowing the growth of pathogenic bacteria in food products were 4.9 (B. cereus), 4.1 (L. monocytogenes), 4.05 (Salmonella spp.) and 4.0 (S. aureus) (Jay et al., 2005). Only $L$. lactis subsp. lactis, L. lactis subsp. cremoris and one isolate of $L$. plantarum produced inhibitory substance(s) with some characteristics (antagonistic activity resistant to supernatant neutralization and sensitivity to proteolytic action) suggesting a bacteriocin-like nature (Jack et al., 1995). According to Todorov (2009), several bacteriocins produced by different strains of $L$. plantarum isolated from food products have been described, for instance, Plantaricin $\mathrm{K}$ produced by $L$. plantarum DK9 isolated from $f u f u$ (Olukoya et al., 1993). The presence of bacteriocin-producing LAB in the puba microbiota could be interesting because the synergism among bacteriocins and organic acids in foods has already been described (Jack et al., 1995; Schillinger and Lücke, 1989).

In conclusion, the similarities in the submerged fermentation processes of puba, lafun and foo-foo, prepared in Brazil and Africa, may explain the similar results reporting the presence of $L$. fermentum, $L$. delbrueckii and $L$. plantarum in staple foods of these different products. This study is the first molecular identification of lactobacilli isolated from market puba. The strong antagonistic effects of the LAB isolates from puba against pathogenic bacteria suggest a potential use for these bacteria as starter cultures for safer and better puba production, which may have a considerable social impact. Indeed, today, a significant portion of the nutritional needs of many consumers in impoverished regions of Brazil is met through fermented foods like $p u b a$, and this probably will expand in the near future.

\section{Acknowledgments}

This study was supported by grants from Fundação de Amparo à Pesquisa do Estado de Minas Gerais (FAPEMIG, CBB APQ - 4172 - 4. 01/07) and Conselho Nacional de Desenvolvimento Científico e Tecnológico (CNPq, process 475024/2009-5).

\section{References}

Adams MR, Nicolaides L (1997) Review of the sensitivity of different foodborne pathogens to fermentation. Food Control 8:227-239.

Almeida EG, Rachid CCTC, Schwan RF (2007) Microbial population present in fermented beverage 'cauim' produced by Brazilian Amerindians. Int J Food Microbiol 120:146-151.

Almeida PF, Moraes IO, Castro RC, Menezes TB (1993) Fermentação de mandioca para a produção de carimã. Ciênc Tecnol Aliment 13:113-120.

Amoa-Awua WKA, Appoh FE, Jakobsen M (1996) Lactic acid fermentation of cassava dough into agbelima. Int J Food Microbiol 31:87-89.

Brauman A, Malonga SKM, Miambi E, Ampe F (1996) Microbiological and biochemical characterization of cassava retting, traditional lactic acid fermentation for foo-foo (cassava flour) production. Appl Environ Microbio 62:2854-2858.

Delfederico L, Hollmann A, Martinez M, Iglesias NG, De Antoni G, Semorile L (2005) Molecular identification and typing of lactobacilli isolated from kefir grains. J Dairy Res 73:20-27.

Fernandes C (2009) Viagem Gastronômica Através do Brasil. In: Alves, MVB (ed) Senac São Paulo, São Paulo, pp 238.

Guyot JP, Ampe F, Omar N (1998) Recovery of total microbial RNA from lactic acid fermented foods with a high starch content. Lett Appl Microbiol 27:270-274.

Hane BG, Jager K, Drexler HG (1993) The Pearson productmoment correlation coefficient is better suited for identification of DNA fingerprinting profiles than band matching algorithms. Electrophoresis 14:967-972.

Holzapfel W (2002) Appropriate starter culture technologies for small-scale fermentation in developing countries. Int J Food Microbiol 75:197-212.

Jack RW, Tagg JR, Ray B (1995) Bacteriocins of Gram positive bacteria. Microbiol Rev 59:171-200.

Jay JA, Loessner MJ, Golden DA (2005) Intrinsic and extrinsic parameters of foods that affect microbial growth. In: Heldman DR (ed) Modern Food Microbiology. Springer Science, New York, pp 39-59.

Kostineck M, Specht I, Edward VA, Schillinger U, Hertel C, Holzapfel WH, Franz CMAP (2005) Diversity and technological properties of predominant lactic acid bacteria from fermented cassava used for the preparation of Gari, a traditional African food. Syst Appl Microbiol 28:527-540.

Lacerda ICA, Miranda RL, Borelli BM, Nunes AC, Nardi RMD, Lachance MA, Rosa CA (2005) Lactic acid bacteria and yeast associated with spontaneous fermentation during the production of sour cassava starch in Brazil. Int $\mathrm{J}$ Food Microbiol 105:213-219.

Moreira JLS, Mota RM, Horta MFM, Teixeira SMR, Neumann E, Nicoli JR, Nunes AC (2005) Identification to the species level of Lactobacillus isolated in probiotic prospecting stud- 
ies of human, animals or food origin by $16 \mathrm{~S}-23 \mathrm{~S}$ rDNA restriction profiling. BMC Microbiol 5:5-15.

Olukoya DK, Tichaczek PS, Butsch A, Vogel RF, Hammes WP (1993) Characterization of the bacteriocins produced by Lactobacillus pentosus DK7 isolated from ogi and Lactobacillus plantarum DK9 from fufu. Chemie Mikrobiol Technol Lebensmittel 15:65-68.

Oyewole OB, Odunfa SA (1990) Characterization and distribution of Lactic acid bacteria in cassava fermentation during 'fufu' production. J Appl Bacteriol 68:145-152.

Padonou SW, Nielsen DS, Hounhouigan JD, Thorsen L, Nago MC, Jakobsen M (2009a) The microbiota of lafun, an African traditional cassava food product. Int J Food Microbiol 133:22-30.

Schillinger U, Lücke FK (1989) Antibacterial activity of Lactobacillus sake isolated from meat. Appl Environ Microbiol 55:1901-1906.
Stiles ME (1996) Biopreservation by lactic acid bacteria. Antonie Leeuwenhoek 70:331-345.

Stephenson DP, Moore RJ, Allison, GE (2009) Comparison and utilization of repetitive-element PCR techiniques for typing Lactobacillus isolates from chicken gastrointestinal tract. Appl Environ Microbiol 75:6764-6776.

Todorov DS (2009) Bacteriocins from Lactobacillus plantarum production, genetic organization and mode of action. Braz $\mathrm{J}$ Microbiol 40:209-221.

Torriani S, Felis GE, Dellaglio F (2001) Differentiation of Lactobacillus plantarum, L. pentosus, and L. paraplantarum by $r e c A$ gene sequence analysis and multiplex PCR assay with $r e c A$ gene-derived primers. Appl Environ Microbiol 67:3450-3454.

Versalovic J, Koeuth T, Lupski JR (1991) Distribution of repetitive DNA sequences in eubacteria and application to fingerprinting of bacterial genomes. Nucleic Acids Res 19:68236831.

All the content of the journal, except where otherwise noted, is licensed under a Creative Commons License CC BY-NC. 